\title{
Successful Treatment of Neuropathic Pain
} with Pulsed Radiofrequency Treatment which Is Induced by PMMA Leakage during Percutaneous Vertebroplasty

\author{
Joohyun Kim, Junseok W. Hur, Jang-Bo Lee, Jung Yul Park ${ }^{凶}$ \\ Department of Neurosurgery, College of Medicine, Korea University, Seoul, Korea
}

\begin{abstract}
A 73-year-old woman with a history of L5 osteoporotic compression fracture treated with percutaneous vertebroplasty at another hospital was admitted due to severe lower extremity pain. Postoperative computed tomography (CT) revealed extravasation of polymethylmethacrylate (PMMA) into the central spinal canal and to the left L5-S1 foramen. She complained of spontaneous ongoing pain, hyperalgesia with electric shock-like sensations over the left L5 and S1 dermatomes and sleep disturbance. The authors confirmed that she has neuropathic pain according to the Leeds assessment of neuropathic symptoms and signs Pain Scale (18) and the Douleur Neuropathique 4 questionnaire score (7). Surgical treatment was reserved after careful consideration of the issues such as delayed time of the PMMA leakage, no further progression of motor weakness (grade 4/5) and development of neuropathic pain. Instead, pharmacological treatment was started with administration of gabapentin and tramadol hydrochloride, but she partially responded to the medications. Thus, we decided to proceed with nerve blocks and observed much improvement of symptoms. Then, pulsed radiofrequency treatment was subsequently performed. The patient's symptoms were controlled to a tolerable level without further medications or interventions during a 1-year follow up period.
\end{abstract}

Key Words: Vertebroplasty; Polymethylmethacrylate; Leakage; Neuropathic pain; Pulsed radiofrequency.

$\triangle$ Corresponding author: Jung Yul Park, Department of Neurosurgery, College of Medicine, Korea University Anam Hospital, 73 Inchon-ro, Seongbuk-gu, Seoul 02841, Korea. Tel: 82-2-920-5729, Fax: 82-2-929-0629, E-mail: jypark98@korea.ac.kr

\section{INTRODUCTION}

Percutaneous vertebroplasty (PVP) with polymethylmethacrylate (PMMA) has been widely used for osteoporotic compression fractures while PMMA leakage continues to be a challenge in procedure related complications. Although not always the case, most of the PMMA leakage yields minimal clinical symptoms ${ }^{12)}$. In rare occasions, severe neurologic symptoms such as motor deficit and severe radiating pain develop, and when patients show those symptoms, surgeons typically perform surgery to remove PMMA. Here, we present a case of a patient who has neuropathic pain progression after the complication of PMMA leakage. The patient's symptoms were controlled by interventional procedure rather than the surgery.

\section{CASE REPORT}

A 73-year-old woman with a 3-month history of intolerable pain and spontaneous paresthesia in the left lower extremity after PVP was admitted to our hospital. Three months ago, she underwent PVP with PMMA to treat an osteoporotic compression fracture on L5 at another hospital due to intractable back pain. According to the operative note, PMMA was injected after confirming the proper needle placement at the left pedicle under biplanar fluoroscopic guidance. Some leakage of the liquid PMMA was noted fluoroscopically, and the procedure was stopped. The amount of injected PMMA was not recorded. Postoperatively performed computed tomography (CT) revealed extravasation of the PMMA into the spinal canal and the left L5-S1 foramen (Fig. 1). Three months after the procedure, she presented to our hospital with spontaneous ongoing pain (VAS 7-8), hyperalgesia with electric shock-like sensations 


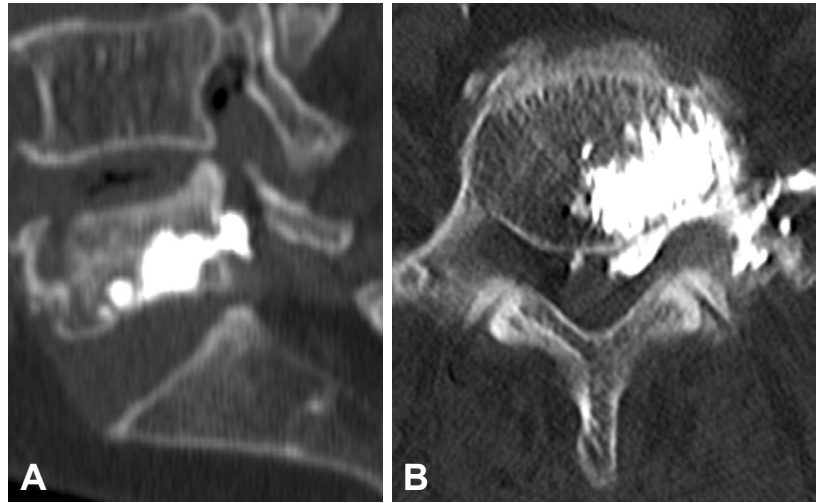

Fig. 1. A : Postoperative sagittal computed tomography demonstrating the partial filling of the vertebral body with polymethylmethacrylate. There is an apparent extrusion of the PMMA posteriorly that fills the left neural foramen. B : Postoperative axial CT at the fifth lumbar level revealing posterior leakage of the PMMA partially surrounding the dura and laterally through the left neural foramen.

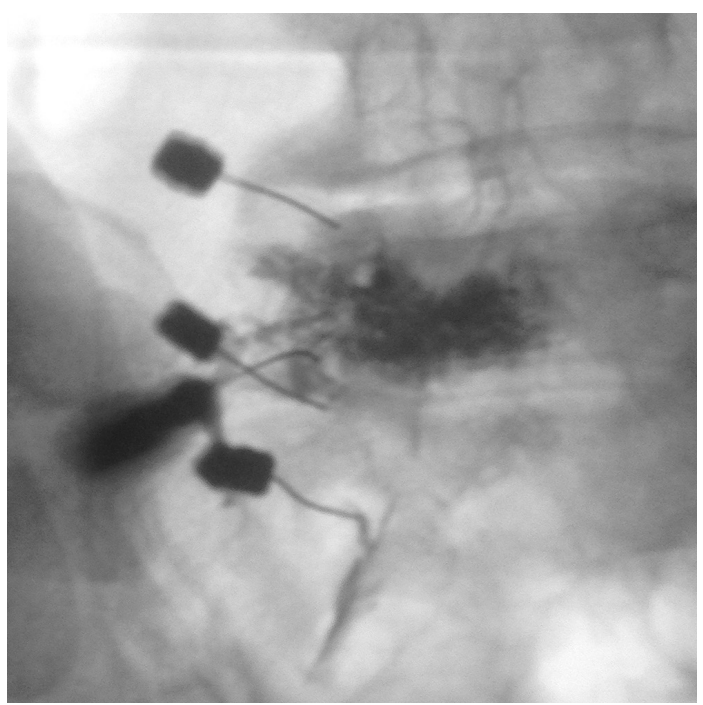

Fig. 2. Plain x-ray showing the needle position on an anteroposterior view aiming for the L5, S1 dorsal root ganglion and the L4, 5 medial branch on the left side.

over the left L5 and S1 dermatomes and sleep disturbance. A neurologic examination revealed a motor deficit (grade 4/5) of the left extensor hallucis longus. Neuropathic pain was identified via the Leeds assessment of neuropathic symptoms and signs (LANSS) Pain Scale (18) and the Douleur Neuropathique 4 (DN4) questionnaire score $(7)^{4,17)}$.

Surgical treatment was reserved after careful consideration of the issues such as delayed time of the PMMA leakage, no further progression of motor weakness and development of neuropathic pain. Instead, pharmacological treatment with a combination of gabapentin titrated at $400 \mathrm{mg} 3$ times daily and tramadol hydrochloride at $50 \mathrm{mg} 3$ times daily was given, but the patient partially responded to the medications. Nerve blocks with a mixture of $1 \%$ lidocaine, steroid, and hyaluronidase (1500 $\mathrm{IU})$, the total of $3 \mathrm{~mL}$, were administered at one week interval, and her symptoms gradually improved (VAS 4-5). After confirming the efficacy of the nerve blocks, PRF treatment was performed targeting the medial branches of left L4, 5 and the dorsal root ganglion of left L5, S1 3 weeks later (Fig. 2). The neurological symptoms and findings were tolerably controlled without further medications or interventions over a 1-year follow up period (VAS 1-2). The motor dysfunction also improved to grade 5/5.

\section{DISCUSSION}

PVP with PMMA has become the main treatment option for osteoporotic compression fractures in patients whose pain is not controlled by non-operative measures ${ }^{10,15}$. While PVP is regarded as a relatively safe procedure, severe neurological complications can still occur if careful attention is not given to the technical details ${ }^{7,15,16}$. The PMMA leakage into the foramen is less frequent than the leakage into the spinal canal even though the risk of nerve root compression in the foramen is reported to be much higher (i.e. $2 \%$ to $8 \%$ of cases $)^{3,121,18,20)}$. From time to time, this nerve-damaging stimuli could generate neuropathic pain with a mechanical or biochemical mechanism ${ }^{2,6}$.

Compression of the neural elements that results in severe neurological injury necessitates urgent surgical intervention ${ }^{12,13,18,20,21)}$. Urgent decompression by laminectomy or foraminotomy could have been helpful in this case, for the patient who exhibited lowgrade motor dysfunction in terms of prevention of permanent neurological damage and intolerable chronic pain. However, when she visited our hospital, she had neuropathic pain and no further progression of weakness due to PVP. Thus, non-operative management was planned as the management of neuropathic pain requires an interdisciplinary approach that is centered around the pharmacological treatment ${ }^{2}$. A combination of gabapentin and tramadol hydrochloride was administered to the patient as a first line therapy, even though the pain did not subside.

PRF treatment has been regarded as a safe and effective procedure for patients who suffer from neuropathic pain ${ }^{19)}$. Although the complete mechanism of PRF has not been fully understood, several reports has explained the mechanism of $\mathrm{PRF}^{1,5,8,9,11)}$. According to a recent report, physical events around the electrode induce transmembrane potentials due to the thermal effects, high intensity electric fields or as a result of both ${ }^{11)}$. This may actually enhance the descending noradrenergic and serotonergic inhibitory pathways, which are intimately involved in the modulation of neuropathic pain ${ }^{11,14}$. Based on this rationale of PRF, interventional treatment was performed to the patient, and her neurological symptoms and findings have been well controlled over a 1-year follow up period.

\section{CONCLUSION}

When the patient first presented with neurologic symptoms including new onset radiating pain and low-grade motor dysfunction after the PMMA leakage, those symptoms could have been improved with urgent decompression initially. However, much time has passed to perform surgery and neuropathic 
pain has developed. As a result, neuropathic pain induced by PMMA leakage into foramen was treated successfully with PRF treatment without surgery.

\section{REFERENCES}

1. Ahadian FM: Pulsed radiofrequency neurotomy : advances in pain medicine. Curr Pain Headache Rep 8 : 34-40, 2004

2. Baron R, Binder A, Wasner G : Neuropathic pain : diagnosis, pathophysiological mechanisms, and treatment. Lancet Neurol 9: 807-819, 2010

3. Barr JD, Barr MS, Lemley TJ, McCann RM : Percutaneous vertebroplasty for pain relief and spinal stabilization. Spine (Phila Pa 1976) 25 : 923-928, 2000

4. Bennett $\mathrm{M}$ : The LANSS Pain Scale : the Leeds assessment of neuropathic symptoms and signs. Pain $92:$ 147-157, 2001

5. Bogduk N : Pulsed radiofrequency. Pain Med 7:396-407, 2006

6. Brisby H : Pathology and possible mechanisms of nervous system response to disc degeneration. J Bone Joint Surg Am 88 Suppl 2 : 68-71, 2006

7. Buchbinder R, Osborne RH, Ebeling PR, Wark JD, Mitchell P, Wriedt C, et al. : A randomized trial of vertebroplasty for painful osteoporotic vertebral fractures. N Engl J Med 361 : 557-568, 2009

8. Byrd D, Mackey S : Pulsed radiofrequency for chronic pain. Curr Pain Headache Rep $12: 37-41,2008$

9. Cahana A, Van Zundert J, Macrea L, van Kleef M, Sluijter M : Pulsed radiofrequency : current clinical and biological literature available. Pain Med 7 : 411-423, 2006

10. Chew C, Craig L, Edwards R, Moss J, O'Dwyer PJ : Safety and efficacy of percutaneous vertebroplasty in malignancy : a systematic review. Clin Radiol 66 : 63-72, 2011

11. Chua NH, Vissers KC, Sluijter ME : Pulsed radiofrequency treatment in interventional pain management : mechanisms and potential indications- a review. Acta Neurochir (Wien) 153: 763-771, 2011

12. Cotten A, Dewatre F, Cortet B, Assaker R, Leblond D, Duquesnoy B, et al. : Percutaneous vertebroplasty for osteolytic metastases and myeloma : effects of the percentage of lesion filling and the leakage of methyl methacrylate at clinical follow-up. Radiology 200 : 525-530, 1996

13. Deramond H, Depriester C, Galibert P, Le Gars D : Percutaneous vertebroplasty with polymethylmethacrylate. Technique, indications, and results. Radiol Clin North Am 36 : 533-546, 1998

14. Hagiwara S, Iwasaka H, Takeshima N, Noguchi T : Mechanisms of analgesic action of pulsed radiofrequency on adjuvant-induced pain in the rat : roles of descending adrenergic and serotonergic systems. Eur J Pain 13 : 249-252, 2009

15. Harrington $\mathrm{KD}$ : Major neurological complications following percutaneous vertebroplasty with polymethylmethacrylate : a case report. J Bone Joint Surg Am 83-A : 1070-1073, 2001

16. Kallmes DF, Comstock BA, Heagerty PJ, Turner JA, Wilson DJ, Diamond $\mathrm{TH}$, et al. : A randomized trial of vertebroplasty for osteoporotic spinal fractures. N Engl J Med 361 : 569-579, 2009

17. Krause SJ, Backonja MM : Development of a neuropathic pain questionnaire. Clin J Pain 19: 306-314, 2003

18. Laredo JD, Hamze B : Complications of percutaneous vertebroplasty and their prevention. Semin Ultrasound CT MR 26 : 65-80, 2005

19. Shabat S, Pevsner Y, Folman Y, Gepstein R: Pulsed radiofrequency in the treatment of patients with chronic neuropathic spinal pain. Minim Invasive Neurosurg 49 : 147-149, 2006

20. Weill A, Chiras J, Simon JM, Rose M, Sola-Martinez T, Enkaoua E : Spinal metastases : indications for and results of percutaneous injection of acrylic surgical cement. Radiology 199 : 241-247, 1996

21. Yang SC, Chen WJ, Yu SW, Tu YK, Kao YH, Chung KC : Revision strategies for complications and failure of vertebroplasties. Eur Spine J 17 : 982 988, 2008 